\title{
A Literature on Cross-culture Leadership in China: Qualities and Ways to Improve
}

\author{
Zhiyi Luo
}

\author{
Xi'an Jiaotong-Liverpool University \\ chandle0118@163.com
}

\begin{abstract}
In the context of increasing global connectivity and the development of China's One-Belt and One-Road policy, crossculture leading has become more and more common, more and more important for not only China but also other countries. Many MNCs start to put more efforts in improving their managers' cross-culture leadership in order to be more competitive when doing international business. Under such conditions, we reviewed the literature and research on cross-cultural leadership and selected it by searching three keywords: cross-culture leadership, cross-culture and crossculture management on Google Scholar and CNKI. Then, the selected research is divided into two major aspects: the qualities of an excellent cross-culture leader and ways of improving cross-culture leadership. We summarize the content of cross-cultural leadership and according to these contents, we also summarize the ways of improving cross-culture leadership, both two parts can be concluded in six parts, which mainly focuses on leaders' cultural adaption ability, leaders' communication skills, leaders' cooperation skills, leading skills, professional skills and leaders' personal characteristics. At the same time, we also find that the current research is all quite scattered from each other and among them lack a systematic link.
\end{abstract}

Keywords: cross-culture leadership, leadership in China, literature review, cross-culture management.

\section{INTRODUCTION}

With the development of internationalization and globalization, more and more corporations have started to do business or cooperate with foreign partners. International business has become more active than ever. Even though nowadays, pandemic covid-19 has brought some negative influences to international business, this does not affect the trend towards constantly increasing international business. Under this globalization trend, international companies need more and more expatriates to do business with foreign countries and leaders play a key role in the whole process. Therefore, leaders who can adapt to the cross-culture environment have become the talent goal of many multinational corporations (MNCs). Scholars as well begin to focus more on cross-culture leadership.

In China, with the implementation of reform and opening up, One Belt And One Road and some other policies, more and more Chinese MNCs have been founded and many Chinese leaders are acting actively in cross-culture management. For the initial stage, many
Chinese leaders relied on learning advanced experience from abroad. Nowadays, as Chinese leaders become more active in the world, many scholars started to study crossculture leadership in China.

According to $\mathrm{He}$, Li and Zheng (2014), in the crosscultural context, cross-culture leadership means the sum of the power exerted by the leaders in leading and guiding the subordinates to achieve the organizational goals [1]. Another definition of cross-culture leadership is that cross-cultural leadership refers to one brand new type of leading activity in which leaders acutely recognize cultural differences, then respect and adapt those differences, lead affairs and lead followers in the context of cross-culture [2]. To sum up, cross-culture leadership means the ability of leaders in adapting to a cross-culture environment and leading expatriates in foreign countries. Before cross-culture leadership, we only need to consider how to lead and manage in a single culture backgrounds. However, with cross-culture leadership, we have to consider the cultural differences among different countries and leaders are required to conduct leadership activities in such complex cultural background. Different 
countries have different cultures, thus when conducting cross-culture management, there might be language problems, cultural shock, stereotypes and many other problems [1]. These are all huge challenges for crossculture leaders. For example, they have to learn foreign languages; they need to be familiar with the host country's cultural background, such as manners. There must be some requirements and advantages for them that make them suitable for this important position. Many scholars have studied cross-culture leadership for the recent 26 years and there has been much academic research in this area. Some scholars specifically raised the capability and qualities a cross-culture leader should possess [3, 1, 2, 4]. Some scholars put forward and summarized the model of cross-culture leadership. Moreover, some other scholars have come up with some useful suggestions and methods for leaders to improve their cross-culture leadership [1, 3, 5, 6, 7]. However, the existing research is relatively scattered, different scholars started from their own point of view, there is a lack of systematic linkage between these different views. In addition, some views of different scholars are repetitive. Moreover, the existing studies mostly focus on expatriate managers in developed countries but lack the development and application of Chinese expatriate managers' leadership, so it still needs further study.

In this literature review, we take cross-culture leadership, cross-culture and cross-culture management as keywords. We searched on CNKI and Google Scholar and found 64 relevant papers in total. We only took papers in the last decade into consideration, which involves 40 papers. After going through these papers' titles and abstracts, we finally selected 13 papers with the strongest relevance from 64 relevant literature.

This literature review will focus on collecting and integrating the research results of previous scholars in the field of cross-culture leadership. This paper is a systematic review of the research done so far on crossculture leadership, especially focusing on Chinese scholars' research and Chinese leaders' practices in cross-culture leadership. Besides the integration and conclusion, some future research directions in this field will be proposed. This literature review can serve as a way to understand the current research on cross-culture leadership and provide guidance and direction for future research as well. The following part will talk about the definition of cross-culture leadership, what qualities and capabilities are needed for cross-culture leadership and how to improve one's cross-culture leadership.

\section{LITERATURE REVIEW OF CROSS- CULTURE LEADERSHIP}

The following part will summarize the selected papers' main ideas and points, and then divide all the papers in to two different parts: the qualities of an excellent cross-culture leader and the ways of improving cross-culture leadership.

\subsection{The qualities of an excellent cross-culture leader}

Firstly, many scholars have raised some basic concept of cross-culture leadership and the qualities an outstanding cross-culture leader need. Some summarized and proposed competency models in cross-culture leadership. Some other scholars also summarized and raised the stages of development of cross-culture leadership.

According to Liu et al. (2020), cross-culture leadership includes intercultural communication competence, intercultural sensitivity, social problem's solving competence, interpersonal competence and selfmonitoring competence [3]. He, Li and Zheng (2014) raise that cross-culture leadership can be divided into two parts: the capability of cross-culture leading and crossculture leaders' leadership influence. As for the capability of cross-culture leading, it requires leaders to possess a high level of intercultural communication ability, intercultural adaptation ability, intercultural integration ability and professional knowledge and skills. For crossculture leaders' influence tactics, it involves leadership power influence and leadership charm influence [1].

Based on He, Li and Zheng (2014)'s research, Liu et al. (2020) raise a competency model of cross-culture leadership of project managers: (1) The first part is difference perception, it covers three parts of capability. Cultural sensitivity refers to "a sensitivity to the importance of cultural differences and to the views of people in other cultures". Individuals with high cultural sensitivity can realize and recognize cultural differences in the process of intercultural interaction and make reasonable attributions from the perspective of another culture. Cultural insight refers to the transformation from unconsciousness to consciousness by observing the real reasons behind behaviors in intercultural interaction. In cross-cultural leadership, information acquisition ability refers to the ability of the project manager to actively obtain culture-related information from multiple channels, such as asking employees. Difference perception is very important for cross-cultural leadership, which is the basis of cross-cultural leadership. It enables project managers to accurately explain the expectations and behaviors of employees and various stakeholders in cross-cultural interaction, and then adopt different leadership styles. (2) The second part is understanding differences. There are also three capabilities in this part. Understanding difference requires leaders to understand and accept differences and put themselves in others' shoes, including cultural empathy, openness to experience, and ambiguity tolerance. Cultural empathy refers to the ability to understand other people's viewpoints and feel other people's feelings. Leaders with 
high cultural empathy can make appropriate empathic responses to other people's situations. Openness to experience means the extent to which an individual is innovative, curious and adventurous. People with greater openness are more likely to engage in cross-cultural work. They are more likely to accept new things, accept changes and take the initiative to learn about different cultures. The degree of tolerance for ambiguity is also an important component of understanding differences. When foreign employees behave differently, those with greater tolerance for ambiguity are more likely to adapt to, accept these differences, and effectively manage the pressure. They are also more suitable for more complex and uncertain positions. (3) The third part of this competency model is self-regulation. Goleman (2017) defines self-regulation as the ability to control or alter destructive impulses and emotions for the individual, and the tendency to judge before acting [8]. This part includes four qualities. Firstly, people with high emotional stability are calm, work well in high-pressure situations and have positive beliefs. Optimism is also an integral part of self-regulation, and the belief that you can "do it" is the biggest motivator. Responsibility is described as a positive state of taking on work and being motivated to achieve goals. Highly responsible people are trustworthy, industrious and self-disciplined, and they are more likely to achieve goals. Finally, introspection is a necessary part of individual self-regulation, which can help project managers grow and make better judgments. (4) The fourth part is vision charisma. This part requires leaders to firstly clarify the team goal and establish a clear and achievable goal for the project. At the same time, the goal can be broken down and foreign employees can participate in setting their own goals. A good goal can guide, unite, motivate and restrain the team at the same time. Second, project managers should inspire their employees and inspire them to believe they can accomplish great things that change their lives. At work, a leader is not just a command. He should motivate employees to explore working methods, guide them to grow, be willing to delegate, give them more autonomy, let them feel their importance and dare to give advice. At the same time, project managers should establish an atmosphere of trust in different cultural environments, so that employees can recognize and follow their leaders. When trust is lacking, the team will be suspicious of each other and do not cooperate with each other, which seriously affects the success of the project. (5) The fifth part of this competency model is caring. Leaders should give more humanized care to employees at work, such as caring for the family and life of subordinates and helping subordinates deal with problems in life and work. Moreover, some countries have a lower power distance compared with the home country, so if project managers adopt domestic paternalistic leadership, conflicts may occur. Therefore, the project manager should give the greatest respect to the personalities of foreign employees and affirm their values. At the same time, the project manager should also respect the local religious beliefs and customs, and do not try to touch the bottom line of local employees. Understanding and enlightening employees are equally important. When employees encounter difficulties at work, they feel pressure. Project managers should help employees deal with psychological pressure and enhance communication, tolerance and understanding of employees. (6) The last part is risk handling. One of the ways to deal with risks is to avoid risks, which requires project managers to have forward-thinking and foresight and make preparations in advance in the face of possible situations. Moreover, certain rules and regulations are also a way to deal with risks. Some foreign employees have a high value of avoiding uncertainty, so the project manager should establish certain rules and regulations when signing the contract, and take certain measures in the face of emergencies so that the employees can work at ease. Resource integration skills can also help project managers cope with risks. In international projects, project managers lack the support of domestic resources and need to actively look for material resources and relational resources, so resource integration is particularly important. Finally, cultural conflicts and interest conflicts occur from time to time in organizations, so project managers should be able to prevent and deal with various conflicts and reduce performance risks caused by organizational conflicts [3].

Cui and Huang (2014) explain the content and mode of cross-culture leadership from some different perspectives. They divide cross-culture leadership into three different components: cognition management, relationship management and self-management Cognition management involves non-judgmentalness, inquisitiveness, tolerance of ambiguity, cosmopolitanism and interest flexibility. As for relationship management, this includes interpersonal engagement, relationship interest, emotional sensitivity, self-awareness and social flexibility. In self-management, it involves optimism, self-identity, self-confidence, non-stress tendency, stress management and emotional resilience. They also raise that a global leader has charisma and the art of organizational construction, which is embodied in the following 12 dimensions: vision, empowerment, energy, planning and adjustment, reward and feedback, team building, extroversion, global awareness, grit, emotional intelligence, work-life balance, and resistance to stress [2]. Moreover, in "Construction of organizational leadership evaluation system for cross-cultural enterprises", Gu, Sun and Liang (2014) conclude six elements of cross-culture leadership: vision orientation, organizational support, organizational operation, team building, cultural integration, and environmental interaction [4].

In Tsai et al. (2019)'s research, they introduce a new mode called cross-culture leadership adjustment (CLA) They raise that modes of CLA could be affected by some 
internal and external factors. Internally, the leaders' own standards of best ways to manage and their own perceptions to adapt their leading approaches with the employee characteristics both can influence their modes of CLA. Externally, the local employee characteristics can also make a big influence on the leaders' decisions whether change their own leading approaches or not. Their study specifically explains some dimensions that can influence a leader's cross-culture leadership adjustment. They also provide some important and unique insights on effective cross-culture leadership [9].

During their research on cross-culture leadership, Cui and Huang (2014) also summarize cross-culture development and its five stages: the first stage is the negative stage, people in mainstream cultural groups have no concept of other cultural groups or do not think they need to interact with others at all. At the organizational level, it manifests itself in a lack of acceptance. The second stage is polarization, in this stage, individuals are aware of the group's cultural differences, but two distinct attitudinal tendencies emerge: defensiveness and reversal. Defensiveness means people believes that their own culture is better than others, and they cling to their own culture rather than accept or appreciate others' culture. As for reversal, it means people believe that other people's culture is better than their own, and they adopt the culture of others and abandon their own culture. The third stage is named as the minimum stage. This stage begins to change from a monocultural world view to a multi-cultural world view. At this stage, individuals begin to pay attention to universal or humanistic concepts, minimize cultural differences, and begin to seek common ground while reserving differences. This stage is the best process to continue the development of the polarization stage, in fact, it is a long process of cross-cultural understanding. The task of development at this stage is to fully understand one's own culture as well as the cultural background of others. The fourth stage is the acceptance stage. In this stage, the task of development is to learn and tolerate cultural differences, so that individuals and organizations can learn how to adapt to the new cultural environment while maintaining their own cultural uniqueness and core values. The last stage is the adaption stage. An organization at this stage is able to get all its members to show the most appropriate behavior in a culturally adaptive way. At this stage, cultural differences are no longer a threat, but a source and power of organizational development [2]. Another research by Fan (2018) raises the development stage of cross-cultural leadership of global leaders: cultural cognition ability -cultural adaptation ability -- cultural integration ability [10].

Moreover, in the study on the transformation of leaders' own cross-cultural management ability into cross-cultural leadership, Bird (2016) believes that leaders' cross-cultural competence should include cross- cultural sensitivity, cross-cultural team cooperation spirit, the ability to seek common ground and at the same time reserving differences, empathy, open thinking, flexible adaptability, tolerance and cultural synergy. In Bird's (2016) theory, cross-cultural sensitivity means sharp adaptability and thinking ability in the new cultural environment. Cross-cultural team cooperation spirit is the key part of cross-culture leadership. It requires members to learn from each other, monitor each other, be intolerant to each other and keep harmony thus improve together. The ability to seek common ground while reserving differences can, based on respecting cultural differences, can make cross-cultural management orderly and achieve the effect of achieving the same goal. Tolerance and empathy refer to being familiar with and understand cultural diversity, considering cultural differences while designing plans or putting them into action, using the potential energy of cultural differences into the kinetic energy of enterprise development, being able to empathize with the differences of different cultures and try one's best to participate in cross-cultural practices and experiences [11].

Different from the research mentioned above, Rašković's (2014) research specifically focuses on the dimension of cultural difference which is one of the affective dimensions of cross-culture leadership. His research indicates that the degree of difference between different countries' leadership styles depend on the cultural similarity among the compared countries. In this comparison, power distance seems to become a vital cultural dimension about the universality of leadership practices. This research result has important enlightenment for cross-culture leadership practice, where special attention should be paid to this cultural dimension [12]. To follow up, Straka et al. (2018)'s research mentions the influence of culture on crossculture leadership. Culture can help MNCs to establish a shared vision among different cultural groups. With the shared vision and goal, communication can become much easier. This makes it easier to build a better partnership. Moreover, culture can also play an important role in motivating others to work harder and more effectively [13].

\subsection{Ways of improving cross-culture leadership}

In recent years, many scholars have also done some research on ways of improving cross-culture leadership. Different scholars studied and summarized the improving measures from different perspectives. The following will present each scholar's different points. All these points can also be divided into the six parts mentioned above: leaders' cultural adaption ability, leaders' communication skills, leaders' cooperation skills, leading skills, professional skills and leaders' personal characteristics. 
Under He, Li and Zheng (2014)'s theory, they raise some ways to improve leaders' cross-culture leadership according to each part of their theory. In their theory, there are two parts of cross-culture leadership, as mentioned above, the capability of cross-culture leading and cross-culture leaders' leadership influence. For improving the cross-culture leaders' leadership influence, leaders need to focus on improving their power influence and charisma influence. There are three ways to improve their power influence: (1) give full play to the legal rights of leaders and reasonable allocation of organizational resources and decision-making. (2) Leaders should reasonably use rewards and punishments to influence others. (3) Leaders should use their expert power to influence others; as for charisma influence, they propose two strategies: (1) enhance the personal quality and personal charm of the leader, and give play to the role of charm. (2) Improve leaders' emotional intelligence and create a good interpersonal relationship and organizational atmosphere. For the capability of crossculture leading, leaders need to work on intercultural communication ability, intercultural adaptation ability, intercultural integration ability and professional knowledge and skills. Each of these has two specific ways for leaders to improve themselves. In order to enhance their intercultural communication ability, they need to (1) respect different cultural customs and habits; (2) keep curious to understand and accept different cultures and take the initiative to carry out cross-cultural communication. As for intercultural adaption ability, it requires leaders to (1) keep learning more knowledge about cross-cultural and be good at looking for the combination of two cultures. (2) Learn to summarize and accumulate cross-cultural conflict solutions and experience. Shaw, Erickson and Nasirzadeh (2015) also raise some important points in intercultural adaption. They believe that expatriate managers should firstly avoid engaging in behaviors and actions that might be considered destructive in their home countries. This might allow them time to learn more about the nuances of effective leader behavior in the foreign environment and enhance their chance of success in cross-culture leading [14]. Then, for improving intercultural integration ability, leaders need to (1) strive to explore the common ground of different cultures and form a common basis for integration. (2) Identify different cultural differences and advantages, promote strengths and complement integration, and form a more reasonable third-party culture. Lastly, to improve professional knowledge and skills, leaders are required to (1) learn more about their professional knowledge and skills. (2) Improve their foresight, decision-making, and execution [1].

Liu et al. (2020) also raise some useful strategies to improve cross-culture leadership. Their views are mainly from the perspective of how can parent companies improve the cross-cultural leadership of expatriate leaders. First, the parent company should attach importance to the selection of expatriate project managers. Expat positions need to be matched with talents to work better. Before the official assignment, the parent company should set up the selection criteria for project managers. The parent company can also provide pre-assignment opportunities prior to the official assignment, providing the project manager to be assigned with local institutions, residents and employees, and gaining experience related to the culture of the host country, so as to help the parent company and oneself determine whether the position is suitable for the assignment. Second, the parent company should carefully design and provide training content and support system before and after the assignment. The training content can include cultural knowledge training and skill training. Cultural knowledge training focuses on understanding the specific cultural environment of the host country. Skills training focuses on specific crosscultural professional skills and leadership skills training. At the same time, the parent company should provide a support system, including not only the analysis and feedback of project data at all times, to guide the operation of the project, but also care for the mental health of the project, to help take care of the domestic family, to relieve the psychological pressure. Finally, project managers should pay attention to their own leadership improvement. The expatriate project manager must improve his/her ability to withstand pressure, be optimistic and cheerful, be good at summarizing, and lead employees on the basis of self-regulation. In the face of cultural conflicts, we must respect local employees, understand and care about their differences in behavior, and maintain adequate communication. At the same time, the project manager should pay attention to team building, establish feasible team goals, and let foreign employees integrate into the team through appropriate authorization and encouragement to play a role in the team. When executing projects overseas, project managers should also do a good job in risk prevention and control, have a sense of the overall situation and forwardlooking thinking, keep a close eye on the situation, and avoid risks with the help of contracts and systems to ensure the controllable project environment [3].

Zhang (2020) has done some research on how Chinese leaders can improve their cross-culture leadership. Firstly, Zhang (2020) believes that leaders must take confidence in the Chinese nation's culture as a deep foundation and also maintain Chinese cultural focus and continue Chinese cultural heritage. Leaders should propose a bilateral and multilateral management system with Chinese characteristics and style, and promotes "harmony without uniformity, seeking common ground while shelving differences", "Harmony and equality, innovation and win-win" management situation Secondly, to improve cross-culture leading capability, leaders should take "Think globally, act locally" as the 
guiding principle. The localization management of human resources in the host country should be implemented by utilizing regional advantages. Crossculture leaders and expatriates should overcome the adverse effects of cultural differences, language barriers, ways of thinking and living habits of expatriates, maintain a good and steady relationship of mutual trust with local owners and government, and promote the longterm development of enterprises and companies in the local area. Thirdly, intercultural training programs and innovative talent training methods should be implemented as systems to train global intercultural leaders. Lastly, the core of enhancing cross-cultural leadership lies in building innovative cross-cultural teams of the Belt and Road Initiative and enhancing cultural soft power. Cross-cultural teams need to set up the "people-oriented" and "global thinking, local operation" concepts and bring the top design into the system of team construction and management innovation. The teams also should take "build human destiny community" as their own duty, set common development and common prosperity of countries along the drive as the highest goal, let the advantages of traditional leadership extend to the cross-cultural leadership [5].

$\mathrm{Mu}$ (2014) as well summarizes some measures to enhance cross-culture leadership. Firstly, cross-culture leaders should enhance the awareness of orderly public diplomacy. Secondly, they should guide organizations in various industries to enhance the ability of selfdiscipline. Thirdly, they should coordinate labor conflicts at home and abroad in order to grasp the rules of communication with new labor organizations. Lastly, they should give full play to the role of intermediaries and respect the freedom of customs and beliefs of all ethnic groups [7].

Under Hua (2013)'s research, there are four ways to improve cross-culture leadership. Firstly, it requires leaders to recognize, understand and then respect the cultural difference. Secondly, to strengthen the responsibility of cross-cultural leadership, recruitment and selection of competent cross-cultural leaders. Effectively identify and recruit leaders who have a high degree of cross-cultural potential. Different cultures require different leadership styles. Choosing leaders who meet the needs of corporate culture integration and can be accepted by the entire organization will be very beneficial to the improvement of crosscultural leadership of Chinese multinational enterprises. Thirdly, leaders should enhance communication and interaction. Nowadays, the mainstream of international politics has shifted from confrontation and contradiction to dialogue and mutual understanding. In international economic exchanges and social life, we also should strengthen communication in order to dispel misunderstanding, enhance understanding, reduce estrangement and seek consensus through communication. Leaders and expatriates should be tolerant of differences and try to seek common ground while shelving differences. Lastly, leaders should learn to keep curiosity. In order to observe or furtherly understand other cultural frameworks, leaders must actively seek them out. Only leaders with genuine curiosity and an open mind can gain cultural acumen. The real understanding of the cross-cultural environment is more dependent on "physical experience". Therefore, it requires cross-cultural managers to be good at dealing with local people and establishing their own networks to experience this new culture. Only by doing this can they empathize and consider their own thoughts and views from new positions and environments [6].

The research mentioned above raises some important points and ideas about cross-culture leadership from different perspectives. What can be concluded is that many scholars focused on cross-culture leadership in the following dimensions: leaders' cultural adaption ability, leaders' communication skills, leaders' cooperation skills, leading skills, professional skills and leaders' personal characteristics. Some even have concluded a model to evaluate the cross-culture leadership of the leaders. However, many of these researches still have not covered all the perspectives that need to notice about cross-culture leadership. Some of these researches are relatively theoretical that seem quite hollow to understand.

Table 1. Frequency of six dimensions of cross culture leadership

\begin{tabular}{|c|c|c|}
\hline Dimension & Author & Frequency \\
\hline $\begin{array}{l}\text { Cultural adaption } \\
\text { ability }\end{array}$ & $\begin{array}{l}\text { Liu et al. (2020), He, Li } \\
\text { and Zheng (2014), Fan } \\
\text { (2018), Bird (2016), } \\
\text { Rašković (2014), Straka } \\
\text { et al. (2018), Erickson and } \\
\text { Nasirzadeh (2015), Mu } \\
\text { (2014), Hua (2013), }\end{array}$ & 9 \\
\hline $\begin{array}{l}\text { Communication } \\
\text { skills }\end{array}$ & $\begin{array}{l}\text { Liu et al. (2020), He, Li } \\
\text { and Zheng (2014), Cui } \\
\text { and Huang (2014), Straka } \\
\text { et al. (2018), Zhang } \\
(2020) \text {, Mu (2014), Hua } \\
(2013) \text {, }\end{array}$ & 7 \\
\hline $\begin{array}{l}\text { Cooperation } \\
\text { skills }\end{array}$ & $\begin{array}{l}\text { Liu et al. (2020), Cui and } \\
\text { Huang (2014), Bird } \\
(2016)\end{array}$ & 3 \\
\hline Leading skills & $\begin{array}{l}\text { Liu et al. (2020), Cui and } \\
\text { Huang (2014), Straka et } \\
\text { al. (2018), He, Li and } \\
\text { Zheng (2014), Zhang } \\
\text { (2020), Mu (2014), } \\
\text { He, Li and Zheng (2014), }\end{array}$ & 6 \\
\hline $\begin{array}{l}\text { Professional } \\
\text { skills }\end{array}$ & $\begin{array}{l}\text { Liu et al. (2020), Erickson } \\
\text { and Nasirzadeh (2015), } \\
\text { Hua (2013), }\end{array}$ & 4 \\
\hline $\begin{array}{l}\text { Personal } \\
\text { characteristics }\end{array}$ & $\begin{array}{l}\mathrm{He}, \mathrm{Li} \text { and Zheng (2014), } \\
\text { Bird (2016), Hua (2013) }\end{array}$ & 3 \\
\hline
\end{tabular}




\section{DISCUSSION}

This paper reviews and summarizes some research on cross-culture leadership. We also systematically divide these research into two parts and then conclude some main dimensions of cross-culture leadership. For theoretical contribution, this paper provides an overview of the overall situation in the field of cross-culture leadership for future research. This paper also makes a simple classification of the whole field, for example, the competency elements of cross-cultural leadership are divided into six parts: leaders' cultural adaption ability, leaders' communication skills, leaders' cooperation skills, leading skills, professional skills, and leaders' personal characteristics.

As for the practical implication of this paper, firstly the research of this paper emphasizes the role of crosscultural leadership, which can attract academic attention and practical attention to improving this ability and accomplishment to a certain extent. Secondly, we give specific suggestions and operational methods for Chinese leaders to improve themselves in the cross-cultural environment. Moreover, this paper also provides a direction for MNCs about how to manage their expatriate employees. Another implication can be inferred from the frequency of Table 1: we can infer that the most important parts of cross-culture leadership include cultural adaption ability, communication skills and leading skills since most of the papers have studied these dimensions.

There are still some limitations in this paper but we also find some future directions. Firstly, we only reviewed 13 papers out of 64 papers, and we only took papers published in the last decade into consideration, thus there are some boundaries of this paper, so the results and conclusions from this paper might be restricted and lack completeness. As for the research method, this paper is a theoretical review, and the subsequent research can adopt quantitative research or empirical research to comprehensively test whether all aspects proposed in this paper can be supported by data. Moreover, this paper focuses on Chinese cross-cultural leaders and may have limitations of applicability. Future research can compare different cultural backgrounds to seek commonness and characteristics. Lastly, considering the severe pandemic covid-19, cross-culture leading can be very different from the normal conditions and very challenging. International conflicts and frictions can also be an obstacle when doing cross-culture leading. Thus, future research on cross-culture leadership can consider such abnormal conditions about how can they affect cross-culture leadership.

\section{CONCLUSION}

This paper focuses on the relevant issues of Chinese leaders' cross-cultural leadership development and puts forward specific cultural situations. A dialogue between Chinese literature and foreign literature is formed to help foreign researchers understand the progress in relevant fields in China. This paper can be helpful for a more thorough understanding of the capabilities of crossculture leadership and identifies a way to enhance crossculture leadership. This paper also provides some useful suggestions for Chinese MNCs to do international business. More importantly, we offer directions and guidance for future researches in this field.

\section{REFERENCES}

[1] He bin, Li Zeying \& Zheng Hong. 2014. Content Structure model and validation of cross-cultural leadership: A case study of Sino-German crosscultural team. Economic management (12), 8394. doi:10.19616/j.cnki.bmj.2014.12.011.

[2] Cui Wenxia \& Huang Zhicheng. 2014. Exploring the development stages and models of cross-cultural leadership from the perspective of globalization. Comparative Education Research (06),1-6. doi:CNKI:SUN:BJJY.0.2014-06-001.

[3] Liu Bing, Wei Xin, Cai Di \& Zhu Naixin. 2020. Cross-cultural leadership structure dimensions of dispatched project managers based on grounded Theory. China Soft Science (04),109-122. doi:CNKI:SUN:ZGRK.0.2020-04-010.

[4] Gu xiaoyong, Sun Jianping \& Liang Ruibing. 2014. The construction of organizational leadership evaluation system in cross-cultural enterprises. Statistics and Decision (23),186-188. doi:10.13546/j.cnki.tjyjc.2014.23.052.

[5] Zhang Yanfang. 2020. On the path to improve the "cross-cultural leadership" of Chinese enterprises. China Leadership Science (04),85-88. doi:CNKI:SUN:KXLD.0.2020-04-018.

[6] Hua Lei. 2013. Cross-cultural extension of leadership. Knowledge Economy (02),2021. doi:10.15880/j.cnki.zsjj.2013.02.139.

[7] Mu Tianxue. 2014. The development of China (Shanghai) Pilot Free Trade Zone calls for the improvement of cross-cultural leadership. Journal of China Executive Leadership Academy Pudong (02),112-115. doi:CNKI:SUN:ZPDG.0.2014-02019 .

[8] Goleman, Daniel. 2017. What Makes a Leader? Harvard Business Review Classics. Harvard Business Review Press. Available at: https://search-ebscohostcom.ez.xjtlu.edu.cn/login.aspx direct $=$ true $\& d b=c a t$ 01010a\&AN=xjtlu.0001309524\&site=edslive $\&$ scope $=$ site. 
[9] Chin Ju Tsai, Chris Carr, Kun Qiao \& Sasiya Supprakit. 2019. Modes of cross-cultural leadership adjustment: adapting leadership to meet local conditions and/or changing followers to match personal requirements?. (9), doi:10.1080/09585192.2017.1289549.

[10] Fan Wei. 2018. Exploring and Verifying the structural dimensions of cultural integration ability of global leaders (Master's thesis, Jiangxi University of Finance and Economics).

https://kns.cnki.net/KCMS/detail/detail.aspx?dbna $\mathrm{me}=\mathrm{CMFD} 201802 \&$ filename $=1018161803 . \mathrm{nh}$

[11] Bird, A., Mendenhall, M. E. 2016. From Crosscultural Management to Global Leadership: Evolution and Adaption. Journal of World Business, 2016(01): 115-126.

[12] Rašković, Matevž. 2014. Measuring Culture Effect Size Differences in Slovenian and Portuguese Leadership Practices: Cross-Cultural Leadership Universality or Contigency? South East European Journal of Economics \& Business (1840118X) 8, no. 2 (November 2014): 7-15. doi:10.2478/jeb2013-0004.

[13] Straka, Tanja M., Payal Bal, Colleen Corrigan, Martina M.I. Di Fonzo, and Nathalie Butt. 2018. Conservation Leadership Must Account for Cultural Differences. Journal for Nature Conservation 43 (June 1, 2018): 111-16. doi:10.1016/j.jnc.2018.03.003.

[14] Shaw, J. B., Erickson, A. and Nasirzadeh, F.. 2015. Destructive leader behavior: A comparison of Australian, American, and Iranian leaders using the Destructive Leadership Questionnaire, International Journal of Cross Cultural Management, 15(3), pp. 329-345. doi: 10.1177/1470595815606740. 